\title{
POTENSI YOUTUBE SEBAGAI SUMBER BELAJAR MATEMATIKA
}

\author{
Muji Suwarno \\ Pendidikan Matematika, Pascasarjana, Universitas Negeri Malang \\ mujisuwarno93@gmail.com
}

\begin{abstract}
Abstrak: Perkembangan tekhnologi dan informasi yang semakin maju membuat teknologi berbasis komputer dapat diaplikasikan dalam dunia pendidikan. Pemanfaatan teknologi komputer dijadikan sebagai media pembelajaran ataupun sumber belajar. Bahkan sudah banyak sumber belajar yang beredar secara online berbentuk $e$-learning. Sebagian besar materi pada $E$ learning berupa teks sehingga sulit dipahami siswa dalam mempelajari matematika karena materi matematika terdapat penjelasan langkah-langkah dalam menyelesaikan permasalahan matematika. Untuk itu, sumber belajar berupa video merupakan salah satu alternatif untuk menggantikan media berbentuk teks. Video pembelajaran yang sudah dibuat dapat diunggah pada situs video-sharing seperti Youtube. Tujuan penelitian ini adalah untuk melihat potensi Youtube sebagai sumber belajar matematika siswa. Penelitian menggunakan pendekatan kualitatif deskriptif dengan peneliti sebagai instrument utama. Peneliti menganalisis sumber belajar matematika yang diunggah beberapa saluran di Youtube dan mengadakan wawancara kepada guru pelajaran matematika dan siswa SMA tentang pendapat Youtube sebagai sumber belajar matematika. Hasil penelitian menunjukan terdapat saluran Youtube yang menyediakan sumber belajar matematika untuk dipelajari siswa sudah cukup baik dijadikan sumber belajar siswa. Berdasarkan wawancara dengan guru matematika dan siswa, Youtube bisa menjadi sumber belajar matematika yang potensial, namun ada beberapa sisi positif serta negatif yang perlu diperhatikan.
\end{abstract}

Kata Kunci. Matematika, Youtube, Sumber Belajar

\section{Pendahuluan}

Data pada tahun 2012 menunjukan bahwa $22 \%$ populasi masyarakat di Indonesia merupakan pengguna internet dan diperkirakan semakin berkembang sitiap tahunnya (Permatasari, 2013). Hal ini dapat dimanfaatkan dalam dunia pendidikan dengan memanfaatkan pembelajaran secara online. Pembelajaran secara online dapat membuat siswa lebih mandiri (Delen, dkk, 2014). Untuk itu, diperlukan sumber belajar secara online yang berupa e-learning. E-learning memiliki banyak keunggulan dibandingkan metode pembelajaran tradisional (Ojeaga \& Igbinedion, 2012). Dalam pembelajaran matematika, materi yang diajarkan bukan hanya berupa pengetahuan, namun juga ada penjelasan tiap langkah penyelesaian masalah dalam matematika yang jika ditulis berupa teks akan manghabiskan berlembar-lembar halaman. Dengan menggunakan video, hal itu dapat diringkas hanya dalam beberapa detik video (Vieira, dkk, 2014). Berdasarkan hal tersebut, e-learning dalam pembelajaran matematika sebagainya berupa video. Video pembelajaran dapat diunggah di internet agar dapat menjadi sumber belajar matematika yang dapat dipelajari siswa secara online.

Salah satu penyedia website video-sharing yang mengizinkan pengguna untuk mengunggah, menonton, dan berbagi video adalah Youtube (Alwehaibi, 2015). Fleck dkk (2014) menyatakan Youtube merupakan tempat dimana setiap pengguna dapat berbagi video secara gratis dan disaksikan jutaan 
penonton setiap hari. Sejak diluncurkan tahun 2005 kepopuleran Youtube (www.youtube.com) semakin meroket sebagai website video-sharing. Pada akhir lima tahun pertama setelah diluncurkan, Youtube menerima lebih dari 2 miliar penonton setiap hari dan pengguna mengunggah lebih dari 35 jam video setiap menit (Snelson, 2011). Banyak penelitian yang membuktikan bahwa Youtube berguna untuk berbagai spesialisasi (Sorensen, dkk, 2014). Youtube bermanfaat untuk berbagai disiplin ilmu seperti perawatan, pembelajaran Bahasa inggris sebagai Bahasa ansing dan masih banyak lagi (June, dkk, 2014). Penggunaan Youtube dalam dunia pendidikan bukanlah hal yang baru. Menurut Fleck, dkk (2014) Youtube sebagai alat pendidikan melahirkan perhatian yang besar untuk menciptakan praktek-praktek pendidikan terbaik. Pada Maret 2009, Youtube mengumumkan peluncuran Youtube Edu yang merupakan koleksi teroganisir dari saluran yang dihasilkan oleh sekolah dan perguruan tinggi. Pada akhir tahun pertama lebih dari 300 sekolah dan perguruan tinggi mengunggah lebih dari 65000 video lectures, berita, dan kehidupan di sekolah. Hal ini hanyalah sedikit dari nilai potensial Youtube di bidang pendidikan (Snelson, 2011).

Tujuan penelitian ini adalah untuk menganalisis potensi Youtube sebagai sumber belajar matematika bagi siswa SMA/MA/SMK serta mengeksplorasi bagaimana cara menjadikan Youtube sebagai sumber belajar matematika.

\section{Metode Penelitian}

Penelitian ini menggunakan pendekatan kualitatif deskriptif. Peneliti sebagai instrumen utama akan mendeskripsikan serta mengeksplorasi tentang Youtube sebagai sumber belajar matematika. Peneliti menganalisis saluran-saluran yang ada di Youtube yang membahas tentang materi-materi pelajaran matematika. Analisis berdasarkan indikator-indikator angket yang sudah dibuat sebagai intrumen pendukung tentang isi video yang memuat pembelajaran matematika yang diunggah pada saluran-saluran di Youtube. Saluran yang menjadi subyek penelitian ini adalah "Ituition Indo", "Agus Nggermanto", dan "Pembelajaran Matematika Lengkap Dan Urut". Dalam penelitian ini juga akan diadakan wawancara kepada 5 guru matematika dan 10 siswa SMA/SMK/MA sebagai triangulasi data dan mengetahui potensi Youtube sebagai sumber belajar matematika bagi siswa.

\section{Hasil dan Pembahasan}

Analisis Saluran "Ituition Indo"

Ituition Indo merupakan salah

satu saluran di Youtube yang mengunggah video pembelajaran matematika. Ituition Indo dapat diakses melalui Internet dengan link https://www.youtube.com/user/iTuitionin $\underline{\text { do. }}$ Intuition Indo tidak hanya mengunggah video pembelajaran matematika namun juga pembelajaran fisika. Sistematika dan pengaturan penempatan video pada saluran ini sudah baik. Video dikategorikan sesuai dengan bab atau pokok bahasan yang akan dijelaskan. Sayangnya, saluran ini hanya mengunggah 3 pokok bahasan yaitu (1) bentuk pangkat, akar, dan logaritma, (2) fungsi dan persamaan kuadrat, dan (3) sistem persamaan linier dua variabel. Saluran Ituition Indo sepertinya tidak mengunggah lagi video pembelajaran matematika. Video terakhir diunggah pada tahun 2012, sehingga materi yang disampaikan pada video berdasarkan kurikulum KTSP.

Pada setiap bab terdiri dari beberapa video dimana tiap video berisi 
penjelasan materi serta contoh pengerjaan soal dari tiap sub bab pada bab yang menjadi pembahasan. Video sudah sesuai dan sistematis sehingga memudahkan siswa untuk belajar dari video yang diunggah tersebut. Isi dari tiap video yaitu penjelasan guru tentang materi pembelajaran matematika dengan menggunakan komputer disertai suara oleh guru. Berikut bentuk salah satu video yang diunggah Ituition Indo.

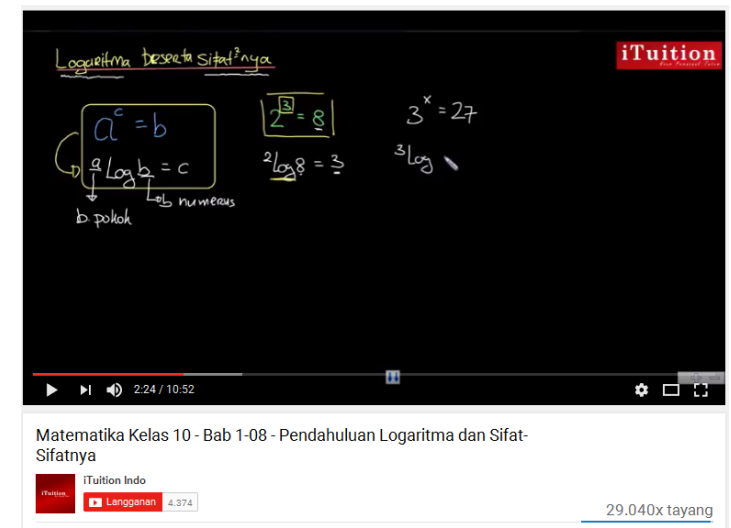

Gambar 1. Video yang diunggah oleh Ituition Indo

Konten video yang diunggah Intuition Indo sudah cukup baik sebagai sumber belajar siswa. Kualitas gambar yang ditampilkan pada video sudah jelas. Suara guru menjelaskan pun sudah jelas. Cara penjelasan guru sudah baik dengan memberikan warna yang berbeda pada tiap tulisan memudahkan siswa untuk memahami materi pembelajaran yang diajarkan.

\section{Analisis Saluran "Agus Nggermanto"}

Agus Nggermanto merupakan salah satu saluran di Youtube yang mengunggah video khusus untuk pembelajaran matematika. Saluran Agus Nggermanto dapat diakses melalui Internet dengan link https://www.youtube.com/user/agusyes. Saluran Agus Nggermanto menyediakan konten-konten pembelajaran matematika dari SD sampai SMA. Penataan video pada saluran ini kurang baik. Video tidak ditata dengan baik disesuaikan dengan kategori-kategori tertentu, sehingga untuk mencari video pembelajaran yang sesuai dengan kebutuhan siswa akan sulit. Sebagian video yang diunggah saluran Agus Nggermanto adalah pembelajaran matematika SD. Video tersebut berisi cara-cara kreatif mengajarkan anak dalam pembelajaran berhitung. Video pembelajaran yang ditujukan untuk siswa SMA hanya sedikit. Agus Nggermanto hanya mengunggah materi sub bab-sub bab tertentu saja dan tidak lengkap. Tidak ada lanjutan dari materi yang sudah dijelaskan pada video tersebut. Agus Nggermanto sudah mengunggah lebih dari dua ribu video sehingga siswa akan mengalami kesulitan jika siswa ingin mengetahui video materi yang diinginkan ada di saluran ini atau tidak. Selain itu, video pembelajaran bagi siswa SMA sederajat adalah tentang penjelasan pengerjaan suatu soal. Guru memberikan suatu soal yang merupakan materi yang masuk sebagai bahan Ujian Nasional dan guru menjelaskan bagaimana cara mudah mengerjakan soal tersebut.

Isi dari tiap video yaitu penjelasan guru tentang materi pembelajaran matematika dengan menggunakan kertas putih dan menggunakan spidol berwarna untuk menjelaskan pembelajaran disertai suara oleh guru. Berikut bentuk salah satu video yang diunggah Agus Nggermanto.

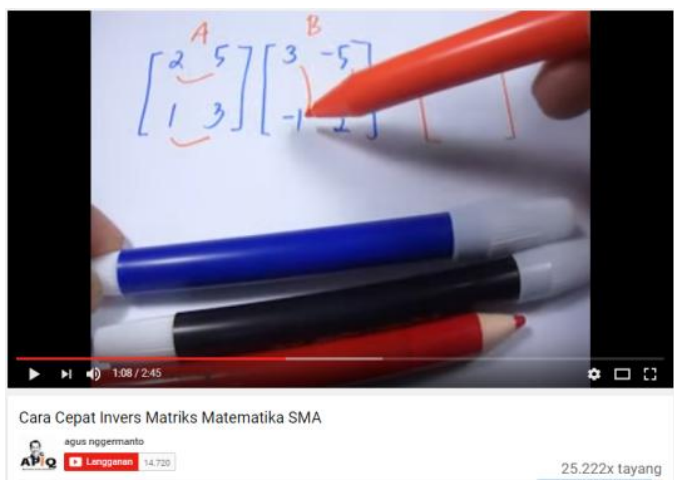

Gambar 2. Video yang diungguh oleh Agus Nggermanto 
Konten video yang diunggah Agus Nggermanto sudah cukup baik sebagai sumber belajar siswa. Kualitas gambar yang ditampilkan pada video sudah jelas, namun jika dibandingkan dengan video yang diunggah Ituition Indo, kualitas gambar pada video Ituition Indo lebih baik. Suara guru menjelaskan juga sudah jelas. Cara penjelasan guru sudah baik dengan memberikan warna yang berbeda pada tiap tulisan memudahkan siswa untuk memahami materi pembelajaran yang diajarkan.

\section{Analisis Saluran "Pembelajaran Matematika Lengkap Dan Urut"}

Saluran Pembelajaran Matematika Lengkap Dan Urut merupakan salah satu saluran yang khusus mengunggah video pembelajaran matematika. Saluran ini dapat diakses dengan link https://www.youtube.com/channel/UCOcJ fLNZWqaQbEC4PDLOJwA.

Dibandingkan dengan saluran Ituition Indo dan Agus Nggermanto, saluran Pembelajaran Matematika Lengkap Dan Urut masih tergolong saluran baru. Saluran ini mengunggah video pertamanya pada bulan Agustus 2016. Sehingga materi yang disajikan merupakan materi terbaru yang sesuai dengan kurikulum 2013. Pengunggahan video yang dilakukan Saluran Pembelajaran Matematika Lengkap Dan Urut rapi dan berurutan. Tiap bab materi yang diunggah oleh Saluran Pembelajaran Matematika Lengkap Dan Urut diawali dengan pendahuluan materi. Pendahuluan berisi tentang peta konsep materi yang disuguhkan pada bab tersebut serta subbab-subbab pada materi tersebut. Video selanjutnya adalah sub bab pertama dari bab tersebut dan seterusnya hingga semua materi tersampaikan. Judul video juga menegaskan untuk melihat deskripsi video yang berisi semua link video dari subbab-subbab pada materi tersebut sehingga memudahkan siswa untuk mempelajari suatu materi secara keseluruhan. Sayangnya, materi yang diunggah Saluran Pembelajaran Matematika Lengkap Dan Urut hanya materi matematika peminatan MIPA yaitu materi (1) eksponen dan logaritma, dan (2) polinomial. Ada kemungkinan saluran Saluran Pembelajaran Matematika Lengkap Dan Urut akan mengunggah video lagi karena saluran ini masih tergolong baru.

Isi dari tiap video yaitu penjelasan guru tentang materi pembelajaran matematika dengan menggunakan kertas bergaris yang sudah ditulis menggunakan bolpoin sebelumnya. Dari materi yang sudah ditulis sebelumnya, guru menjelaskan materi pembelajaran disertai suara oleh guru. Berikut bentuk salah satu video yang diunggah Saluran Pembelajaran Matematika Lengkap Dan Urut.

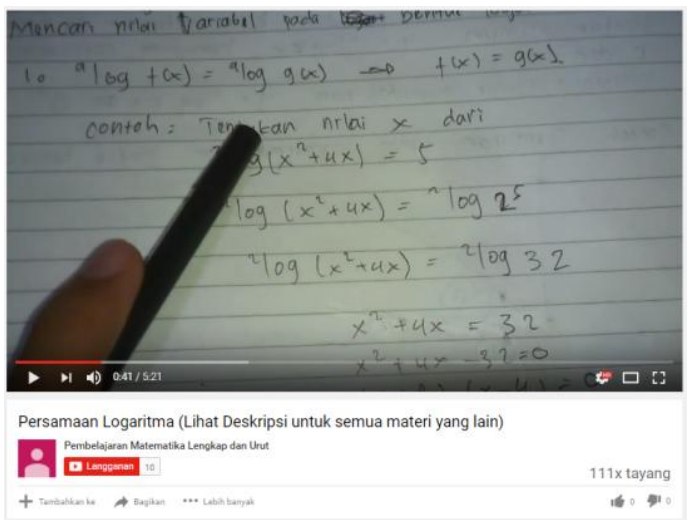

Gambar 3. Video yang diungguh oleh Pembelajaran Matematika Lengkap Dan Urut

Konten video yang diunggah Pembelajaran Matematika Lengkap Dan Urut sudah cukup baik sebagai sumber belajar siswa. Kualitas gambar yang ditampilkan paling bagus diantara saluran yang dibahas pada penelitian ini. Suara guru menjelaskan juga sudah jelas. Cara penjelasan guru sudah baik meskipun konten materi sudah ditulis terlebih 
dahulu. Sistematika penjelasan materi juga sudah baik.

\section{Analisis Youtube Sebagai Sumber Belajar Matematika}

Youtube sebagai sumber belajar sudah banyak digunakan banyak sekolah dan perguruan tinggi di luar negeri (Snelson, 2011). Berdasarkan analisis yang sudah dijelaskan pada beberapa saluran Youtube di atas, video materi pembelajaran matematika yang ada di Youtube bisa menjadi sumber belajar baik. Namun, kekurangan dari saluransaluran tersebut adalah tidak semua materi pembelajaran matematika lengkap pada satu saluran. Untuk mencari materi yang diharapkan oleh siswa, siswa perlu mencari di mesin pencari Youtube untuk menemukan video pembelajaran yang sesuai dengan yang diharapkan.

Untuk menggunakan Youtube sebagai sumber belajar secara optimal menurut Burke dan Snyder (2008) dapat menggunakan beberapa langkah yaitu (1) pergi ke www.youtube.com pada internet browser, (2) pada bagian pencarian yang ada di bagian atas ketikan kata kunci, judul atau istilah untuk mencari video yang dikehendaki, (3) klik tombol "cari", (4) layar pada internet browser akan muncul daftar judul video beserta screenshot video yang tersedia dan memenuhi kriteria kata kunci yang telah dimasukan, (5) pilih video yang terlihat sesuai dengan subyek yang diinginkan dengan mengklik screenshot video. Video yang dipilih akan dimainkan, (6) di bagian bawah layar video, terdapat pilihan untuk berhenti, mundur, mampercepat, memperbesar video, mengatur volume suara. Ada juga timer yang menampilkan panjang video, (7) setelah video selesai diputar, terdapat pilihan untuk meneruskan video lain atau menonton lagi. Judul dan screenshot dari video lain dengan isi yang serupa juga ditampilkan secara otomatis, (8) terdapat pilihan menyimpan video di situs Youtube (dengan menambahkan pada "Favorit" atau "Add to Playlist"), atau menyalin URL video dari kotak navigasi dan menggunakannya untuk membuat link sehingga lebih mudah untuk digunakan di kelas, (9) pengguna juga dapat mengakses informasi tambahan tentang menonton video dan fungsi Youtube lain dengan mengklik link "Bantuan".

Berdasarkan analisis saluransaluran di Youtube, Youtube memiliki potensi sebagai sumber belajar matematika yang baik. Untuk memastikan hal tersebut, diadakan wawancara dengan guru matematika dan siswa SMA. Semua guru matematika yang menjadi partisipan dalam penelitian ini tidak pernah menggunakan Youtube sebagai sumber belajar matematika. Sedangkan 3 dari 10 siswa yang menjadi partisipan pernah menggunakan Youtube sebagai sumber belajar matematika. Namun, sebenarnya partisipan yang pernah menggunakan Youtube sebagai sumber belajar matematika tidak sengaja menemukan video pembelajaran matematika di Youtube. Mereka mencari cara suatu materi di mesin pencari Google, kemudian mendapati video di Youtube yang sesuai dengan keinginan siswa.

Guru matematika juga berkomentar tentang penggunaan Youtube sebagai sumber belajar matematika. Ada dampak positif dan dampak negatif jika menggunakan Youtube sebagai sumber belajar siswa. Dampak positif penggunaan Youtube sebagai sumber belajar siswa yaitu (1) lebih menarik bagi siswa karena berupa video dibandingkan sumber belajar berupa teks dan (2) jika siswa lelah belajar matematika, siswa dapat beralih untuk refreshing dengan melihat video- 
video hiburan yang ada di Youtube. Sedangkan dampak negatif Youtube sebagai sumber belajar siswa yaitu (1) Video yang tidak sesuai dengan pembelajaran dapat mengalihkan siswa saat mempelajari materi matematika di Youtube dan (2) tidak cocok bagi siswa yang "kuno". Guru matematika yang menjadi subyek penelitian ini menyarankan untuk dikembangkan suatu saluran Youtube yang berisi pembelajaran matematika yang lengkap dan sistematis berdasarkan kurikulum yang berlaku saat ini. Dengan adanya saluran seperti itu, guru dapat mengunduh video yang ada pada saluran tersebut dan membagikannya kepada siswa sehingga dapat mengurangi dampak negatif penggunaan Youtube.

Siswa yang menjadi partisipan dalam penelitian ini berpendapat jika Youtube bisa menjadi sumber belajar matematika yang baik jika ada arahan dari guru video mana saja yang dapat digunakan sebagai sumber belajar siswa. Siswa merasa kebingungan dengan banyaknya video yang ada di Youtube. Terkadang, siswa juga menemukan judul video yang diinginkan siswa, namun isi video tersebut tidak sesuai dengan judul video. Peran guru sangat diperlukan dalam penggunaan Youtube sebagai sumber belajar. Guru dapat memilah video dan memberitahu kepada siswa video yang dapat digunakan sebagai sumber belajar siswa.

\section{Kesimpulan}

Berdasarkan hasil dan pembahasan dapat disimpulkan bahwa saluran-saluran Youtube yang menyediakan pembelajaran matematika dapat dijadikan sumber belajar yang baik bagi siswa. Namun, dari semua saluran yang menjadi subyek penelitian, tidak ada saluran yang menjadi sumber belajar matematika secara lengkap. Youtube merupakan sumber belajar matematika yang potensial meskipun ada beberapa dampat negatif. Saran dari penelitian ini adalah ada praktisi pendidikan matematika yang membuat saluran di Youtube khusus untuk pembelajaran matematika yang berisi pembelajaran lengkap dan sistematis berdasarkan kurikulum 2013. Informasi tentang saluran tersebut dapat disebarluaskan kepada guru dan siswa agar dapat menggunakan video yang ada pada saluran Youtube tersebut sebagai sumber belajar matematika.

\section{Daftar Rujukan}

Alwehaibi, H.O. 2015. The Impact of UsingYouTube In EFL Classroom on Enhancing EFL Students' Content Learning., Journal of College Teaching \& Learning, 12(2), 121-126.

Burke, S. C., \& Snyder, S. L. 2008. YouTube: An Innovative Learning Resource for College Health Education Courses., International Electronic Journal of Health Education, 11, 39-46

Delent, E., Liew, J., \& Willson, V. 2014. Effects of Interactivity and Instructional Scaffolding on Learning: Selfregulation in Online Video-based Environments., Computers \& Education, 78, 312320.

Fleck, B.K.B., Beckman, L.M., Stern, J.L., \& Hussey H.D. 2014. YouTube in the Classroom: Helpful Tips and Student Perceptions, The Journal of Effective Teaching, 14(3), 21-37.

June, S, Yaacob, A., \& Kheng, Y.K. 2014. Assessing The Use Of Youtube Videos And Interactive Activities As A Critical Thinking Stimulator For Tertiary Students: 
An Action Research, International Education Studies, 7(8), 56-67.

Ojeaga I. J., \& Igbinedion, V. I. 2012. Potentials of E-learning as a Study Tool in Business Education in Nigerian Schools, International Education Studies, 5(5), 218-215.

Permatasari, H.P., Harlena, S., Erlangga, D., \& Chandra, R. 2013. Effect of Social Media on Website Popularity: Differences between Public and Private Universities in Indonesia, World of Computer Science and Information Technology Journal (WCSIT), 3(2), 32-37.
Snelson, C. 2011. YouTube across the Disciplines: A Review of the Literature, MERLOT Journal of Online Learning and Teaching, 7(1), 158-169.

Sorenson, J. A., Pusz, M. D., \& Brietzke, S. E. 2014. Youtube As An Information Source For Pediatric Adenotonsillectomy And Ear Tube Surgery, International Journal of Pediatric Otorhinolaryngology, 78, 65-70.

Vieira, I., Lopes, A.P., \& Soares, F. 2014. The Potential Benefits Of Using Videos In Higher Education, Proceedings of EDULEARN14 Conference, 750-756. 